\title{
Práticas discursivas afro-brasileiras: a irrupção de saberes dominados nas mídias
}

\author{
Afro-Brazilian discursive practices: the outbreak of dominated knowledge in the \\ media \\ Claudemir Sousa \\ Universidade Estadual Paulista Júlio de Mesquita Filho (UNESP)
}

\begin{abstract}
RESUMO: neste artigo se discute a proliferação de saberes e práticas afrodescendentes no espaço heterotópico da web (GREGOLIN, 2015). Para tanto, foram selecionados dois sites, quais sejam: "Portal Geledés" e "Mundo Negro", os quais compõem um arquivo sobre as discursividades afro-brasileiras. Essa discussão ancora-se nos pressupostos da arqueologia de Michel Foucault, do qual são mobilizados os conceitos de saber, práticas discursivas e dispositivo (FOUCAULT, 2008; 2013a; 2013b); nas teorizações de Neves (2015), sobre o dispositivo colonial; e de Ianni (1988), Proença Filho (2004) e Duarte (2007; 2011) sobre a literatura afro-brasileira, para encetar uma possível conceituação para as práticas discursivas afro-brasileiras.
\end{abstract}

PALAVRAS-CHAVE: Práticas discursivas. Saberes dominados. Afro-descendência.

ABSTRACT: this article discusses the proliferation of Afro-descendant knowledge and practices in the heterotopic space of the web (GREGOLIN, 2015). For this purpose, two sites were selected, namely: "Portal Geledés" and "Site Mundo Negro", which composes an archive on Afro-Brazilian discourses. This discussion are anchored in the assumptions of Michel Foucault's archeology, mobilizing the concepts of knowledge, discursive practices and devices (FOUCAULT, 2008; 2013a; 2013b); Neves' (2015) theorizations about the colonial device; and Ianni (1988), Proença Filho (2004) and Duarte $(2007 ; 2011)$ on Afro-Brazilian literature, for a possible conceptualization of Afro-Brazilian discursive practices.

KEYWORDS: Discursive practices. Dominated knowledge. Afro-descendants.

\section{Introdução}

Ora, na medida em que nós negros estamos na lata de lixo da sociedade brasileira, pois assim o determina a lógica da dominação, caberia uma indagação via psicanálise. E justamente a partir da alternativa proposta por Miller, ou seja: por que o negro é isso que a lógica da dominação tenta (e consegue muitas vezes, nós o sabemos) domesticar? E o risco que assumimos aqui é o do ato de falar com todas as implicações. Exatamente porque temos sido falados, infantilizados (infans, é aquele que não tem fala própria, é a criança que se fala na terceira pessoa, porque falada pelos adultos), que neste trabalho assumimos nossa própria fala. Ou seja, o lixo vai falar, e numa boa (GONZALES, 1984, p. 225). 
Essa fala de Lélia Gonzales aponta para um duplo fenômeno: por um lado, os riscos de se assumir o ato de falar, que pode trazer consequências as mais diversas. Por outro, a necessidade de não mais ter sua vida traduzida pelo outro. Historicamente, os veículos midiáticos não constituíam um espaço no qual sujeitos afrodescendentes podiam falar, e sim um domínio no qual são falados por outrem, constituindo-se em objeto de discurso, fenômeno que Duarte (2011) denomina de negrismo.

Tal discussão nos conduz às formulações de Foucault (2008) sobre as modalidades enunciativas, que respondem pelas questões "quem fala?" e "de quem recebe legitimação para isso?". Existe uma hierarquia dos saberes nas sociedades, que inferioriza e despreza os "saberes dominados" (idem, 2013a), constantemente silenciados pelo dispositivo colonial (NEVES, 2015), uma heterogeneidade de elementos, como a língua, os saberes e as instituições responsáveis por instalar os valores europeus nas Américas, cuja marca ainda se faz sentir, dado o seu caráter de novidade e criatividade (DELEUZE, 1996).

Por essa razão, neste artigo pretende-se discutir como, no interior das práticas discursivas elaboradas pelos dispositivos de saber-poder que atuam em relação aos sujeitos afrodescendentes e tentam despersonalizá-los por diferentes processos, ocorre a irrupção de saberes dominados (FOUCAULT, 2013a) e de práticas discursivas afrocentradas no espaço heterotópico da web (GREGOLIN, 2015). Tais saberes são chamados de dominados porque têm que lutar contra os privilégios dados aos saberes que gozam de reconhecimento social, elaborados por sujeitos cujo status lhes credibiliza essa operação.

As práticas discursivas afro-brasileiras conformam um universo amplo, englobando práticas religiosas, culturais, literatura, música, dança, práticas estéticas que afrontam os padrões de beleza eurocêntricos, saberes estatísticos sobre a vida, a violência, o acesso a direitos sociais, a maneira como moram, se alimenta, adoecimento, etc., e também as disposições legais e instituições que regulam a vida de tais sujeitos.

Dada a abrangência desse universo de práticas, a discussão feita nesse artigo está restrita à análise de dois sites que compõem um arquivo sobre as discursividades afrobrasileiras na atualidade, quais sejam: "Portal Geledés" e "Mundo Negro". Interessa, particularmente, as práticas discursivas elaboradas pelos sujeitos afrodescendentes, com base nos estudos de Ianni (1988), Proença Filho (2004) e Duarte (2007; 2011) sobre a 
Literatura Afro-brasileira, nos quais eles conceituam essa literatura conforme o papel que o negro ocupa, ou seja, se ele é um tema do branco, se tem protagonismo nessa tematização e se pode se configurar como autor que fala do universo afro-brasileiro.

As condições de emergência das práticas discursivas afro-brasileiras enquanto consciência, ou seja, como um movimento voluntariamente organizado para pôr em discussão esse tema, podem ser consideradas com o início dos estudos Afro-brasileiros, nos anos de 1940, com Roger Bastide, sociólogo francês que se dedica ao estudo do candomblé da Bahia e da poesia afro-brasileira, quando chega ao Brasil, em 1938, para compor o corpo docente da Universidade de São Paulo (USP). Esse movimento é influenciado pelo New Negro Moviment, ocorrido nos Estados Unidos da América (EUA) nos anos de 1920, que reuniu artistas, escritores, poetas e músicos no combate ao racismo.

Outros acontecimentos respondem igualmente pelas condições de emergência dessas práticas, como a criação da Frente Negra Brasileira (FNB), em 1931, e a fundação do Teatro Experimental do Negro (TEN), em 1944, por Abdias do Nascimento. Esse sociólogo pregava a ideia de Quilombismo como forma de denunciar o genocídio da população negra do Brasil e apregoar a afro-descendência como o futuro do país, contrariando as teorias raciais que viam os cruzamentos das raças como a causa da degenerescência e atraso do país (SCHWARCZ, 1993). Assim, a ideia de Quilombismo é também uma ruptura com a eugenia e o nazifascismo.

Nos anos de 1960/70, o mundo passa por movimentos de contracultura, entre eles o Black is Beautiful, a revolução sexual, as lutas feministas e pela libertação da África colonizada por europeus, que conduziu à ideologia do Pan-Africanismo. Nesse contexto ocorre, em 1978, a criação do Movimento Negro Unificado Contra a Discriminação Racial (antes MNUCDR e hoje MNU) e dos Cadernos Negros, pelo Grupo Quilombhoje, tornando-se um veículo difusor da literatura produzida por autores negros.

Esse processo foi essencial para a fundação, em 1979, do Centro de Cultura Negra do Maranhão $(\mathrm{CCN})$, iniciativa que é posterior à criação do Grupo Palmares, em Porto Alegre, no Rio Grande do Sul (RS), no ano de 1971, responsável pela proposta de substituição das comemorações do dia 13 de maio como dia de libertação dos negros escravizados a partir da assinatura da Lei Áurea pela Princesa Izabel, pela rememoração 
do dia 20 de novembro como Dia da Consciência Negra, em função da data da morte de Zumbi dos Palmares, em 1695, que liderou negros nas fugas e lutas contra a escravidão. Os militantes desse grupo viabilizaram a publicação do Jornal Tição, a revisão da história dos negros nos livros didáticos e denúncias da violência policial contra a população negra.

Finalmente, o revisionismo crítico da história dos negros no Brasil, ocorrido entre 1980 e 2000, provoca uma crise de paradigmas, desvelando uma série de saberes acerca da formação da nossa sociedade, padrões de beleza, acesso à terra, moradia e outros direitos sociais por parte da população afrodescendente, sua participação nas instituições, questionamento do chamado "mito da democracia racial", que muitos atribuem a Gilberto Freyre, bem como a organização de centros de culta negra em diversos estados.

Dessa forma, esses acontecimentos respondem pela irrupção de enunciados sobre os sujeitos afrodescendentes formulados por esses próprios sujeitos. Longe de tentar perscrutar as origens dessas modalidades enunciativas, busca-se, nas descontinuidades e não linearidade da história (FOUCAULT, 2008), analisar como essas práticas de resistência, que são elaboradas discursivamente, chocando-se com as estratégias de poder que tentam despersonalizar e inferiorizar os sujeitos afrodescendentes no Brasil.

Essa discussão está ancorada nos pressupostos da arqueologia de Michel Foucault, compreendida aqui como um método de análise das discursividades locais, ou seja, dos saberes dominados libertos da sujeição a que estão submetidos pelos blocos de saberes que os concebem como menores diante de sua pretensão de verdade e cientificidade.

Para tanto, os conceitos aqui mobilizados são os de saber, modalidades enunciativas e dispositivo (FOUCAULT, 2008; 2013a; 2013b), que serão discutidos no próximo tópico, junto às teorizações de Neves (2015), sobre o dispositivo colonial. Em seguida, recorre-se às discussões de Ianni (1988), Proença Filho (2004) e Duarte (2011), sobre literatura afro-brasileira, para auxiliar a encetar uma conceituação das práticas discursivas afro-brasileiras. Depois, apresenta-se uma análise dos dois sites e, por fim, serão apresentadas as considerações finais. 


\section{Desdobramentos da Arqueologia do Saber em dispositivos}

Para situar o conceito de "práticas discursivas afro-brasileiras", faremos um retorno à "Arqueologia do Saber" (FOUCAULT, 2008) em articulação com textos nos quais Foucault teoriza acerca dos dispositivos e como esse último se volta ao saber para se desdobrar em linhas de poder e de subjetividade. Dessa forma, compreendemos que a "Arqueologia do Saber" é uma obra que funda a noção de "arqueologia" como método de análise, o qual se faz pela investigação da objetivação dos sujeitos por saberes e requer um retorno às tecnologias de poder e às práticas de subjetivação.

No capítulo final de "Arqueologia do Saber", Foucault (2008) reconhece ter dado atenção, em suas análises, às ciências, assim como às disciplinas ainda em formação, abandonando outras, e se questiona sobre a relação entre a análise arqueológica e análise das ciências. Essas análises ajudaram a descrever positividades e formações discursivas que constituem certos saberes considerados científicos.

A análise arqueológica busca mostrar as regras segundo as quais uma prática discursiva forma grupos de objetos, conjuntos de enunciações, jogos de conceitos, séries de escolhas teóricas, elementos formados por uma prática discursiva e indispensáveis para constituir uma ciência. É isso que Foucault (2008, p. 204) chama “saber”, ou seja,

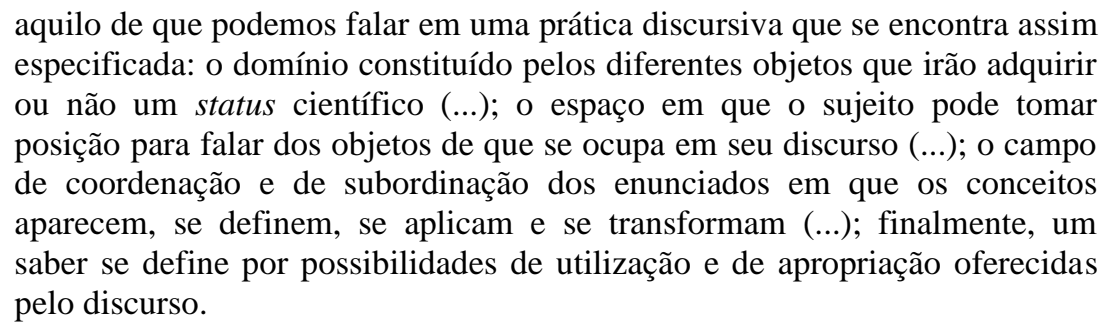

Para esse autor, não há saber sem uma prática discursiva definida e toda prática discursiva pode ser definida pelo saber que forma. É no saber que a arqueologia encontra o ponto de equilíbrio de sua análise das formações discursivas, estudando o sistema de formação dos objetos, dos tipos de enunciação, dos conceitos e das escolhas teóricas.

Em vista do fato de que a arqueologia priorizou o saber científico, Foucault (2008, p. 215) questiona: "seria possível conceber uma análise arqueológica que fizesse aparecer a regularidade de um saber, mas que não se propusesse a analisá-lo na direção das figuras epistemológicas e das ciências?". Sua resposta é que é possível sim uma 
arqueologia em direções diferentes das ciências, visto que "esse é apenas o ponto preferencial da abordagem; não é um domínio obrigatório para a arqueologia" (idem, p. 219).

Nesse sentido, ao se interrogar sobre as relações de poder e a constituição do sujeito em uma ética e estética de si, ele direciona o olhar para os "saberes dominados", os quais são considerados como abaixo do nível de cientificidade desses blocos de saber por ele interrogados. As discussões de Foucault (2013a) sobre os saberes dominados apontam para o procedimento com o qual se estabeleceram eficazes críticas descontínuas, locais e particulares às coisas, instituições, práticas e discursos, que ele denomina de "retorno de saber", querendo dizer com isso a temática não mais do saber, mas da vida; não do conhecimento, mas do real. Tal temática produziu, segundo o autor, a "insurreição dos saberes dominados" (idem, p. 266).

Por "saberes dominados" esse autor compreende, primeiro, os "conteúdos históricos que foram sepultados, mascarados em coerências funcionais ou em sistematizações formais" (FOUCAULT, 2013a, 266). Tais saberes constituem blocos que, mesmo presentes, são mascarados pelas organizações funcionais e sistemáticas, podendo aparecer com a crítica e por meio do instrumento da erudição.

Em uma segunda acepção, os saberes dominados são uma série de saberes que foram desqualificados como não competentes ou insuficientemente elaborados, tidos como ingênuos, inferiores em termos de conhecimento ou de cientificidade. Eles foram colocados embaixo, desqualificados em relação a outros saberes. Também são denominados de "saber das pessoas". Não se trata de um saber comum, e sim de um saber particular, regional, localizado, incapaz de unanimidade. Assim, segundo o autor, foi o reaparecimento desse saber que realizou a crítica.

A insurreição dos saberes dominados é posta em termos de um embate entre o saber da erudição e o saber desqualificado. Com isso, delineou-se uma genealogia ou múltiplas pesquisas genealógicas. Na concepção de Foucault (2013a), a genealogia é o acoplamento do saber erudito com o saber das pessoas, e só foi possível realizá-la com a eliminação da tirania dos discursos totalitários.

Nesse sentido, a genealogia visa combater os efeitos de poder de um discurso que se considera científico e verdadeiro como forma de desqualificar outros saberes. Isso faz da genealogia um empreendimento para libertar da sujeição os saberes. Trata-se 
de uma reativação dos saberes locais contra as hierarquias e seus efeitos de poder. Esse projeto se articula com a arqueologia, na medida em que, para Foucault (2013a, p. 270), a arqueologia é o método de análise da dicursividade local, ao passo que a genealogia "é a tática que, a partir da discursividade local assim descrita, ativa os saberes libertos da sujeição que emergem dessa discursividade”. Assim, o que está em jogo na insurreição dos saberes dominados é saber quais são os dispositivos de poder que se exercem em variados níveis da sociedade, em diferentes domínios e extensões.

Essa discussão conduz ao tema do dispositivo, conceito empregado por Foucault (1999a), em 1976, em "História da Sexualidade 1: a vontade de saber", para tratar de dois tipos de dispositivo: o de aliança e o de sexualidade, mostrando a relação entre ambos, e depois desenvolvido em uma entrevista, de 1977 (FOUCAULT, 2013b), acerca de conceitos empregado naquela obra. Ao definir o conceito de dispositivo, são apresentados três sentidos. No primeiro caso, ele diz o que segue:

Por esse termo tento demarcar, em primeiro lugar, um conjunto decididamente heterogêneo que engloba discursos, instituições, organizações arquitetônicas, decisões regulamentares, leis, medidas administrativas, enunciados científicos, proposições filosóficas, morais, filantrópicas. Em suma, o dito e o não dito são os elementos do dispositivo. O dispositivo é a rede que se pode estabelecer entre estes elementos (FOUCAULT, 2013b, p. 364).

Essa primeira definição se refere aos elementos que compõem e conferem natureza heterogênea ao dispositivo e à relação entre eles. Nele, estão os enunciados, os discursos, de diferentes áreas do saber que constroem um dado objeto, e as instituições das quais esses elementos discursivos partem. Já a segunda definição especifica as relações entre os elementos do dispositivo, conforme Foucault (2013b, p. 364):

Em segundo lugar, gostaria de demarcar a natureza da relação que pode existir entre estes elementos heterogêneos. Sendo assim, tal discurso pode aparecer como programa de uma instituição ou, ao contrário, como elemento que permite justificar e mascarar uma prática que permanece muda; pode ainda funcionar como reinterpretação desta prática, dando-lhe acesso a um novo campo de racionalidade. Em suma, entre estes elementos, discursivos ou não, existe um tipo de jogo, ou seja, mudanças de posição, modificações de funções, que também podem ser muito diferentes.

A análise dessa relação entre o dito e o não dito, o discursivo e o não discursivo, serviu para que ele realizasse suas análises de temas como a loucura, a produção de riqueza, a linguagem, a penalidade e a sexualidade. Quanto à terceira conceituação, tem a ver com a função do dispositivo, como se vê: "em terceiro lugar, entendo dispositivo como um tipo de formação que, em um determinado momento histórico, teve como 
função principal responder a uma urgência. O dispositivo tem, portanto, uma função estratégica dominante" (FOUCAULT, 2013b, p. 365).

Assim, o dispositivo, como elemento de natureza estratégica, está relacionado aos jogos de poder e também a configurações de saber. Ele deve responder às demandas históricas. Esse conceito de dispositivo foi reelaborado por Deleuze (1996) como um conjunto de múltiplas linhas, de diferentes naturezas, que seguem direções distintas, aproximam-se e se distanciam. Essas linhas têm como características o saber, o poder e a subjetividade, elementos que estão indistintamente ligados.

As duas primeiras dimensões do dispositivo destacadas por Foucault (2013b) são nomeadas como "curvas de visibilidade" e "curvas de enunciação" por Deleuze (1996). Elas têm por função fazer ver e fazer falar. Trata-se da dimensão do saber. A terceira dimensão do dispositivo são as linhas de força, que envolvem o dizer e o ver. Ela é a dimensão do poder, responsável pela função estratégica do dispositivo. A última dimensão são as linhas de subjetivação, na qual está em jogo o processo de produção de subjetividade em um dispositivo. Para Deleuze (1996), trata-se de uma linha de fuga, que escapa às anteriores e se volta para si mesmo, e o si mesmo "é um processo de individuação que diz respeito a grupos ou pessoas, que escapa tanto às forças estabelecidas como aos saberes constituídos" (idem, p. 3). Nesse sentido,

\footnotetext{
Os dispositivos têm, então, como componentes linhas de visibilidade, linhas de enunciação, linhas de força, linhas de subjetivação, linhas de ruptura, de fissura, de fratura que se entrecruzam e se misturam, enquanto umas suscitam, através de variações ou mesmo mutações de disposição (idem, p. 4).
}

Daí decorre que o sujeito é resultado de um processo de objetivação e subjetivação dos dispositivos, que se definem pela novidade e pela criatividade que detêm, que marcam sua possibilidade de transformação, fissura, para o surgimento de outro dispositivo. As linhas de força agem na produção das linhas de subjetivação.

Neves (2015) propõe o conceito de dispositivo colonial, a partir do conceito de dispositivo, de Foucault (2013b), e da definição de colonialidade do poder, de Walter Mignolo. Ela trata das tecnologias de poder atuantes na produção de subjetividades das sociedades amazônicas e nos discursos sobre elas, entre as quais está a língua portuguesa, difundida pelo governo português e pela Igreja Católica como oficial na América portuguesa, que viria a ser o Brasil e a arquitetura europeia, que alterou as paisagens das cidades brasileiras ao longo dos séculos. Essas tecnologias continuam 
atuantes, dado a novidade e criatividade do dispositivo. Ao mesmo tempo, as resistências dos sujeitos às linhas de força (DELEUZE, 1996) desses dispositivos se atualizam.

O dispositivo colonial atuou marginalizando as línguas indígenas e africanas diante da língua oficial, bem como as práticas culturais e religiosas desses sujeitos, visto que funciona pela hierarquização, inferiorizando saberes das sociedades não europeias, concebidas como atrasadas e selvagens, ao passo que as europeias são consideradas como modernas, civilizadas, evoluídas. Esse dispositivo se imbrica com outros, como o religioso, as mídias, o sistema judiciário, o dispositivo escolar, as conversas cotidianas.

Dessa forma, gostaríamos de compreender como, no interior das resistências ao dispositivo colonial (NEVES, 2015), se elaboram práticas discursivas afro-brasileiras nas quais irrompem os saberes dominados. As práticas discursivas afro-brasileiras surgem pelo estabelecimento de linhas de fratura, munindo-se do que há de novidade e criatividade no dispositivo colonial. O dispositivo é instituído por saberes, produz saberes, está inscrito em relações de poder e produz subjetividade. É a relação entre esses elementos que está em questão. Para compreender essas práticas é necessário voltar-se para diferentes lugares, e, em nosso caso, voltamo-nos para os enunciados que circulam nas mídias e que se engendram na história e moldam os sujeitos afrodescendentes.

\section{Por um conceito de práticas discursivas afro-brasileiras}

O conceito de práticas discursivas de Foucault (2008, p. 123) consiste em "um conjunto de regras anônimas, históricas, sempre determinadas no tempo e no espaço, que definiram, em uma dada época e para uma determinada área social, econômica, geográfica ou linguística, as condições de exercício da função enunciativa". Os discursos não são formados por uma vontade individual, e nem se deve buscar as suas origens, e sim analisar suas condições de emergência, que são da ordem da história, de certos espaços e se repartem em objetos, conceitos, modos de enunciar e estratégias.

Essa análise leva em conta os seguintes princípios: da dispersão, pois os enunciados não se agrupam de forma linear; de regularidade, que permite agrupar enunciados dispersos sob um mesmo princípio organizador formulado pelo analista; de 
descontinuidade, que caracteriza a história não linear; e de raridade, pois nem tudo pode ser dito e nem todos são autorizados a enunciar, visto que há uma ordem discursiva regulando a proliferação dos enunciados.

Essas discussões de Foucault (2008) podem ser aproximadas das teorizações sobre a literatura afro-brasileira. Duarte (2011) considera que muitos negros no Brasil não se declaram negros devido aos estigmas que a escravização trouxe para o imaginário social sobre esses sujeitos: até o século XIX, o termo negro era quase sinônimo de escravo.

A assunção de um lugar enunciativo de negro é uma das diretrizes que esse autor utiliza para conceituar a literatura afro-brasileira. Duarte (2007) lança mão de cinco características que julga relevantes para diferenciá-la da literatura brasileira canônica, quais sejam: tema, autoria, ponto de vista, linguagem e público leitor. Tais características, elencadas a partir das problematizações de Ianni (1988) e Proença Filho (2004), auxiliam-nos a encetar uma conceituação para as práticas discursivas afrobrasileiras.

Em primeiro lugar, o tema ou objeto de que se fala nas práticas discursivas afrobrasileiras é o sujeito afrodescendente. As práticas discursivas afro-brasileiras são aquelas que se debruçam sobre os aspectos humano, social, histórico, cultural, político e artístico dos sujeitos afrodescendentes. Nelas, estão englobadas práticas religiosas, danças, músicas, literatura, festas, práticas de ética e estética de si, etc. Essas temáticas são tratadas perpassando a história da diáspora dos negros, passando pelas denúncias da escravidão, suas consequências para os negros na contemporaneidade, as lutas por liberdade e os atuais desafios na luta por direitos e contra a discriminação racial. A denúncia da exclusão nos subúrbios, da marginalidade, da prisão e da violência policial são temas recorrentes nas práticas discursivas afro-brasileiras.

Esse ponto foi suscitado por Ianni (1988) e também por Proença Filho (2004, p. 161, grifos do autor), que vê nos enunciados sobre o negro brasileiro no âmbito da literatura uma trajetória ambivalente: "a condição negra como objeto, numa visão distanciada, e o negro como sujeito, numa atitude compromissada". A primeira

configura-se em textos nos quais o negro ou o descendente de negro reconhecido como tal é personagem, ou em que aspectos ligados às vivências do negro na realidade histórico-cultural do Brasil se tornam assunto ou tema. Envolve, entretanto, procedimentos que, com poucas exceções, indiciam ideologias, atitudes e estereótipos da estética branca dominante (PROENÇA FILHO, 2004, p. 161). 
Já a segunda se caracteriza como "texto do negro", no qual sujeitos afrodescendentes ultrapassam o estereótipo e assumem o seu discurso e sua ação em defesa da identidade cultural afro-brasileira, em uma autoafirmação da etnia. Essa distinção entre sujeito e objeto não é feita aqui de forma rígida, já que estamos pensando com Foucault (2008) a noção de objeto de discurso como regra de formação discursiva.

$\mathrm{O}$ segundo ponto concerne à autoria, que equivale à noção de "modalidades enunciativas" em Foucault (idem), ou seja, "quem fala" nos enunciados. As práticas discursivas afro-brasileiras são elaboradas por sujeitos afrodescendentes. Deve-se considerar a ascendência e o fenótipo como fatores relevantes para determinar essa autoria e não confundir com as práticas discursivas em que outros sujeitos falam sobre o negro, fenômeno ao qual Duarte (2007) denomina, no âmbito da literatura, de negrismo, ou seja, a mera utilização de assuntos atinentes aos negros pelos brancos.

Um passeio pelas práticas discursivas brasileiras vai nos mostrar um conjunto de enunciados e práticas elaboradas por sujeitos brancos. As linhas de força (DELEUZE, 1996) do dispositivo colonial (NEVES, 2015) impuseram uma ordem discursiva que estabeleceu uma lei de silêncio para os sujeitos afrodescendentes no que concerne ao exercício das modalidades enunciativas (FOUCAULT, 2008). Os primeiros enunciados que formam uma memória histórica do Brasil foram produzidos por viajantes, e consistem de relatórios enviados à coroa portuguesa falando das impressões da terra "conquistada", como é o caso da Carta de Pero Vaz de Caminha; documentos da administração colonial, estabelecendo regras de conduta no interior do território que passou às mãos portuguesas; e registro do cotidiano na colônia, feito por pintores como Frans Janszoon Post, Jean-Baptiste Debret e Johann Moritz Rugendas. Indubitavelmente, tais enunciados não pertencem às práticas discursivas afro-brasileiras.

Mesmo se nos encaminharmos para a literatura brasileira, temos uma série de práticas discursivas nas quais o negro é um mero tema do branco. Por outro lado, há uma literatura na qual diferentes autores enunciam sobre o negro, do lugar de negro. Essa tradição se inicia com Luiz Gama e Maria Firmina dos Reis, perpassa a obra de Cruz e Sousa e desemboca em autores contemporâneos, como Conceição Evaristo.

Postular a necessidade de que essas práticas discursivas sejam elaboradas pelos sujeitos afrodescendentes para falar de si, em detrimento daquilo que os brancos falam dos negros, não significa dizer que o branco não possa falar do negro. A história do 
Brasil sempre foi contada pelo viés dos brancos, que se colocaram no centro e reservaram um lugar periférico, quando não de invisibilidade, para os negros. Assim, sempre houve condições para os brancos falarem e se colocarem no centro dessas narrativas, e essas condições vão continuar existindo, a despeito de nós.

O que se propõe é que os negros também possam falar de si; que a periferia das narrativas ou as zonas silenciadas possam exercer as modalidades enunciativas (FOUCAULT, 2008). A experiência desses sujeitos na história contada por eles mesmos tem, a nosso ver, muito mais legitimidade do que a sua possível tradução pelo viés de outrem, visto os espaços que negros e brancos habitam na sociedade é racialmente dividido. É por isso que é necessário confrontar os discursos sobre os sujeitos afrodescendentes com os discursos dos afrodescendentes.

O terceiro fator para caracterizar as práticas discursivas afro-brasileiras é o ponto de vista, também relacionado às "modalidades enunciativas" (FOUCAULT, 2008), compreendidas agora como a posição que se toma para enunciar. O autor dessas práticas deve assumir uma perspectiva que se identifique com a problemática inerente à vida da população afrodescendente. Para tanto, deve se enunciar como um sujeito negro, que se vincula aos aspectos que fundamentam a história dos afrodescendentes. Nesse sentido,

a adoção de uma visão de mundo própria e distinta da do branco, se faz com
a superação da cópia de modelos europeus e de toda a assimilação cultural
imposta como única via de expressão. Ao superar o discurso do colonizador
em seus matizes passados e presentes, a perspectiva afro-identificada
configura-se enquanto discurso da diferença e atua como elo importante
dessa cadeia discursiva (DUARTE, 2007, p. 108).

O ponto de vista adotado nas práticas discursivas afro-brasileiras é uma forma de enfrentar o dispositivo colonial (NEVES, 2015). Ele fundamenta também o estilo de linguagem ou as opções vocabulares empregadas pelo sujeito que enuncia, e esse é o quarto ponto referente à caracterização das práticas discursivas afro-brasileiras. A linguagem nelas utilizada demarca o processo transcultural que o Brasil vive em decorrência da diáspora negra. Nessas práticas, constrói-se um universo discursivo marcado por uma linguagem com traços oriundos de África, que adquirem tonalidades fonológicas, morfológicas, sintáticas e semânticas novas, em face da visão hegemônica da língua portuguesa. Essa ressignificação das linguagens se faz necessária porque 
não há linguagem inocente, nem signo sem ideologia. Termos como negro, negra, crioulo ou mulata, para ficarmos nos exemplos mais evidentes, circulam no Brasil carregados de sentidos pejorativos e tornam-se verdadeiros tabus linguísticos no âmbito da "cordialidade" que caracteriza o racismo à brasileira (DUARTE, 2007, p. 108).

Problematizar essa linguagem se faz necessário para fundar uma prática discursiva que seja veiculada pelo viés dos sujeitos afrodescendentes. Seja nas modalidades textual, visual, sonora ou audiovisual dessas práticas, as opções estéticas e o estilo de linguagem afrontam padrões adotados como corretos pela cópia de modelos europeus. A língua nas quais as práticas discursivas afro-brasileiras se expressam pode ser denominada de "pretuguês", termo empregado por Gonzalez (1984, p. 235), para caracterizar a língua da cultura brasileira, fundada sob a égide dos ensinamentos da “mãe preta”, mucama que repassou os valores para as crianças brasileiras. Segundo ela:

É engraçado como eles gozam a gente quando a gente diz que é Framengo. Chamam a gente de ignorante dizendo que a gente fala errado. E de repente ignoram que a presença desse $r$ no lugar do 1 , nada mais é que a marca linguística de um idioma africano, no qual o 1 inexiste. Afinal, quem que é o ignorante? Ao mesmo tempo, acham o maior barato a fala dita brasileira, que corta os erres dos infinitivos verbais, que condensa você em cê, o está em tá e por aí afora. Não sacam que tão falando pretuguês (idem, p. 238).

Esse "pretuguês" representa uma língua com características que revelam a colonização europeia e escravização negra, ao mesmo tempo em que desnuda as formas de resistência negra, que se manifesta nos sincretismos. Muitas palavras empregadas em nossa língua proveem do quimbundo, língua do tronco linguístico Bantu.

Finalmente, a quinta característica das práticas discursivas afro-brasileiras é o objetivo de formar um público "marcado pela diferença cultural e pelo anseio de afirmação identitária" (DUARTE, 2007, p. 109). Tais práticas têm um viés instrucional para o público afrodescendente, que é compreendido como universo recepcional e fator de intencionalidade, e polemizam com o dispositivo colonial (NEVES, 2015).

Essa finalidade se expressa na criação da impressa negra, a partir de 1915; na fundação do TEN, em 1944; na publicação dos Cadernos Negros, a partir de 1978; e na criação de diversos sites, a partir dos anos 1990, para mediar as relações dos sujeitos afrodescendentes com práticas discursivas atinentes ao seu universo. Nesses outros lugares heterotópicos da web (GREGOLIN, 2015) novos conceitos emergem.

Dessa forma, as práticas discursivas afro-brasileiras são aquelas feitas por sujeitos afrodescendentes em uma operação de resgate, de libertação dos saberes dominados (FOUCAULT, 2013a) da submissão aos saberes que os hierarquizam. 


\section{Práticas discursivas afro-brasileiras nas mídias: a irrupção de saberes dominados}

Gostaríamos de analisar as práticas discursivas afro-brasileiras presentes nos dois sites selecionados mostrando, primeiro, os princípios a que obedecem, em seguida, como essas práticas se relacionam com o dispositivo colonial (NEVES, 2015) e, por fim, os objetos, conceitos, posições enunciativas e escolhas estratégicas (FOUCAULT, 2008) que fazem emergir. Assim, não faremos uma análise exaustiva desses portais.

Para situar os princípios que regulam a construção das práticas discursivas, apresentaremos a descrição dos dois sites. A primeira, do "Portal Geledés", o descreve do seguinte modo:

Geledés Instituto da Mulher Negra fundada em 30 de abril de 1988. É uma organização da sociedade civil que se posiciona em defesa de mulheres e negros por entender que esses dois segmentos sociais padecem de desvantagens e discriminações no acesso às oportunidades sociais em função do racismo e do sexismo vigentes na sociedade brasileira (PORTAL GELEDÉS, 2020, página inicial).

Já o site "Mundo Negro", enuncia os seus propósitos da seguinte forma:

O Mundo Negro foi um dos primeiros portais feito para negros no Brasil. No ar desde 2001 ele é um dos principais sites com conteúdo exclusivo para negros, produzidos por jornalistas, sendo um espaço de notória credibilidade, o que numa era repleta de "produtores de conteúdo", garante ao portal um destaque em comparação aos demais veículos voltados para esse público (MUNDO NEGRO, 2020, página inicial).

$\mathrm{Na}$ dispersão enunciativa (FOUCAULT, 2008) que os caracteriza, ou seja, na sua existência não linear, esses portais apresentam como regularidade o tema ou objeto que põem em discurso: o universo afro-brasileiro. A autoria de ambos é de mulheres negras, que exercem a função enunciativa dessa posição discursiva, propondo-se veicular conteúdos sob um ponto de vista afro-orientado, para um público negro, como seu universo recepcional (DUARTE, 2007). No nível das diferenças, o Geledés propõese a defender as mulheres, o que não emerge nos objetivos do Mundo Negro.

O Geledés - Instituto da Mulher Negra foi criado pela filósofa Sueli Carneiro, em 1988, em São Paulo, e o site, em 1997, também por ela. Já o "Mundo Negro" foi criado pela jornalista Silvia Nascimento. Ambos se constituem em um espaço 
pedagógico para os internautas ao propugnar a difusão de saberes para um público negro, feito por negros.

Esses sites obedecem a um princípio de raridade (FOUCAULT, 2008), segundo o qual nem tudo pode ser dito, já que se constituem em um espaço de eclosão de saberes dominados (idem, 2013a) sobre sujeitos negros, fazendo funcionar uma ordem discursiva oposta àquela dominante, ou seja, um regime que exclui os saberes hegemônicos de circularem nesse espaço alternativo, volta para si e escapa aos saberes constituídos (DELEUZE, 1996).

Essas práticas discursivas se relacionam com o dispositivo colonial (NEVES, 2015) na medida em que surgem no interior das formas atualizadas desse dispositivo, constituindo práticas de resistência. Nessas mídias, a enunciabilidade e a visibilidade atuam fazendo falar e deixando ver aquilo que se interdita na grande mídia, porque não deve circula livremente nela. Os sujeitos afrodescendentes nem sempre podem enunciar e ser vistos na grande mídia, e se eles não estão no regime de luz desse dispositivo não existem para ele. É por essa razão que elaboram formas de resistência nas mídias alternativas e sociais digitais, mobilizando uma linguagem que rompe os padrões de normatização linguística calcados no português europeu, tencionando os efeitos do dispositivo colonial (NEVES, 2015), como se vê na apresentação do Portal Geledés.

Quanto aos objetos, conceitos, posições subjetivas e estratégias (FOUCAULT, 2008) que esses sites põem em circulação para elaborar práticas discursivas afrobrasileiras, podem ser apontadas nos seus menus, que apresentam saberes dominados.

\section{Figura 1 - Menus do Portal Geledés PORTALGELEDÉS.}

Fonte: Portal Geledés - página inicial, 2020

A página principal do Geledés apresenta um menu com hiperlinks para informações diversas, que constituem as práticas discursivas afro-brasileiras, relativas a conceitos, objetos, modos de enunciar e estratégias temáticas (FOUCAULT, 2008) sobre gênero, raça, discriminação, preconceito e África e sua diáspora. Trata-se da proliferação de saberes dominados (idem, 2013a) que fazem frente à lógica dominante, 
que invisibiliza esses temas contados de um ponto de vista que se quer negro (PROENÇA FILHO, 2004).

Dessa forma, os objetos de que se fala nessas práticas discursivas afro-brasileiras veiculadas no Portal Geledés vão se repartindo em conceitos. O objeto gênero reparte-se em: mulher negra, populações LGBTQI+ e violência contra mulher. As questões raciais, fazem emergir os conceitos de cotas raciais, violência racial e policial e relato de casos de racismo. O objeto discursivo discriminação e preconceito se reparte em casos de preconceitos e instrui os sujeitos a defenderem-se da discriminação racial sofrida. Por fim, o objeto diáspora africana nos coloca diante de informações sobre as diversas Áfricas que se formaram nesse processo, na Europa e nas Américas.

O tema da mulher negra que emerge nesse portal afronta a estrutura social brasileira, assentada em um regime colonial patriarcal e racista, conduzida por homens, de ascendência europeia, pele clara e que exclui mulheres e homens negros da condução da vida pública. Essa conjugação dos temas do racismo e da identidade de gênero ganha condições de possibilidade com a constituição de 1988, que tornou o racismo crime, e com o Estatuto da Igualdade Racial, instituído em 2010, com a Lei 12.288, rechaçando a ideia de que vivemos uma democracia racial.

Esse último tema é atribuído a Freyre (2003), para quem os contatos entre os povos que formaram o Brasil não eram de um antagonismo explícito, já que, para ele, houve desagregação de culturas por processos mais sutis e ritmo mais lento do que em outras partes do continente americano. Ele considera que há um "ajustamento de tradições e de tendências raro entre povos formados na mesma circunstância imperialista de colonização moderna dos trópicos" (idem, p. 231).

Gonzales (1984) indaga as causas da aceitação do mito da democracia racial, seu processo de construção, aquilo que ele esconde e qual a mulher negra que esse discurso situa. Para ela, o racismo é "a sintomática que caracteriza a neurose cultural brasileira" (idem, p. 224, grifos da autora), porque se trata de ocultar para se beneficiar. Os saberes dominados que emergem nesse site afrontam esse mito de que não existe racismo.

Já o tema da África e sua diáspora, que emerge nesse portal, possui como condições de possibilidade as diretrizes educacionais dadas com a Lei 10.639/2003, que modificou a Lei no 9.394/1996, de Diretrizes e Bases da Educação Nacional (LDB), para incluir no currículo oficial da Rede de Ensino a obrigatoriedade da temática 
"História e Cultura Afro-Brasileira", tencionado os saberes hegemônicos sobre a formação brasileira.

Esse conjunto de temas ou objetos discursivos emergem e se reconfiguram nos movimentos sociais, nas disposições legais e nos saberes dominados (FOUCAULT, 2013a) que circulam nas heterotopias da web (GREGOLIN, 2015), potencializando a sua exposição pública por sujeitos que se enunciam negros falando para negros.

Desse modo, o Geledés incorpora as categorias de raça e sexo para promover um processo instrutivo da identificação étnico-racial de mulheres negras, fazendo frente às normas raciais e sexuais impostas socialmente, o que implica uma dupla vinculação a grupos marginalizados socialmente (mulheres e negros).

Já o site Mundo Negro se apresenta como um veículo de encorajamento da população afro-brasileira, por meio de uma postura de tomada de posição e de singularização da identidade. A idealizadora do site rompe com a visão da identidade de nação una e coesa, que constitui uma ficção baseada em essencialismos e universalismos, e que oculta a desqualificação dos saberes do e sobre o negro brasileiro.

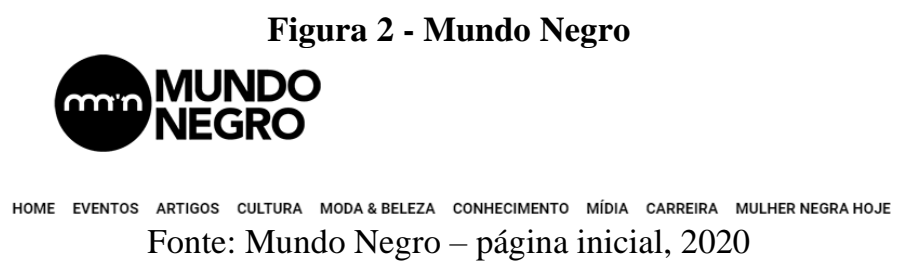

As práticas discursivas desse site repartem-se nos seguintes objetos de que se fala: "eventos" de artistas negros nacionais e internacionais; "artigos" que fazem emergir saberes sobre o universo afrodescendente, como casos de racismo e outros aspectos das relações étnico-raciais; "cultura", com discussões relativas ao universo de artistas afrodescendentes do Brasil e de outros países; "moda e beleza", no qual sobressaem questões relativas ao cabelo de homens e mulheres negras, cuidado com a pele e vestimentas; "conhecimento", com discussões de pessoas negras sobre relações étnico-raciais e sobre educação nessa área; "mídia", na qual há uma profusão de reportagens sobre conteúdos de entretenimento na televisão com pessoas negras e a vida desses famosos; "carreira", com sugestões de cursos, vagas de empregos e suporte 
empresarial para pessoas negras; e "mulher negra hoje", que traz discussões sobre negras famosas.

Particularmente em relação aos temas "moda e beleza" e "mulher negra", destaca-se o cabelo das mulheres negras como forma de desconstruir saberes e discursos pejorativos a esse respeito que propugnam o alisamento como forma de normalizar o comportamento das mulheres negras. O branqueamento, ou seja, "a lógica da dominação que visa a dominação da negrada mediante a internalização e a reprodução dos valores brancos ocidentais" (GONZALEZ, 1984, p. 237), é uma forma de desvelar o mito da democracia racial, pois a existência de proposição de formas de se enquadrar nos padrões estéticos europeus evidencia que há sim racismo, desrespeito e não harmonia racial.

No Brasil, as mulheres negras adquiriram o hábito de usar panos na cabeça para cobrir os cabelos, o que servia para identificar seu estado civil, sua origem africana, representava a grandeza social, a superioridade sexual nas disputas de beleza entre as negras, forma de se proteger do sol e uma forma litúrgica de proteção contra mauolhado.

Segundo Gonzales (1984), existe uma relação contraditória com a mulher negra, de mostrar e esconder, que remonta às práticas escravistas, nas quais essas mulheres eram utilizadas como "mucamas", ou seja, serviçais domésticas, práticas essas que incluíam cuidado com a casa, com os filhos dos senhores e atos sexuais forçados com os homens brancos. Na atualidade, esse jogo de luz e sombra se manifesta na concepção dessa mulher como objeto de prazer, mas não viável para o casamento. Ao mesmo tempo em que essa mulher é endeusada no carnaval, no seu cotidiano é transfigurado na empregada doméstica, que está do lado do permitido na medida em que é servil, mas sofre toda sorte de exclusão.

Dessa maneira, a emergência das práticas discursivas afro-brasileiras nas mídias revela as inquietações e revoltas dos negros com a difusão apenas de saberes sobre os brancos e padrões de beleza europeizados, buscando caminhos alternativos para valorizar aquilo que os caracteriza. Para tanto, esses dois sites articulam etnia, gênero e questões sociais para alimentar o orgulho dos sujeitos afrodescendentes frente aos preconceitos. 
Esses sites exercem, portanto, um papel de resgate da autoestima da população afrodescendente pela reversão de estereótipos e valores implantados pelo dispositivo colonial (NEVES, 2015), propondo novos modelos identitários, combatendo preconceitos e discriminações, questionando a história que marginaliza os afrodescendentes.

\section{Considerações finais}

Para analisarmos como na atualidade ocorre a irrupção de saberes dominados nas mídias, buscamos suportes em práticas discursivas afro-brasileiras veiculadas em dois sites: o Portal Geledés e o site Mundo Negro. Essa discussão foi orientada pelas teorias de Foucault, sobre as práticas discursivas, os saberes dominados e o dispositivo; de Neves (2015) sobre o dispositivo colonial; e de Ianni (1988), Proença Filho (2004) e Duarte $(2007 ; 2011)$ sobre as características da literatura afro-brasileira. Iniciamos esse texto com as discussões teóricas de Foucault e seus interlocutores e, posteriormente, dos autores da literatura para desenvolver o concito de "práticas discursivas afrobrasileiras".

Em seguida, pela análise dos dois sites, concluímos que esses portais se configuram como um conjunto de práticas discursivas afro-brasileiras feitas por mulheres negras, direcionadas a um público negro, veiculando conteúdo de um ponto de vista afro-orientado. Para tanto, os sujeitos afrodescendentes que neles falam se munem das linhas de subjetivação do dispositivo colonial (NEVES, 2015). Nesses postais, emerge um conjunto de objetos discursivos e conceitos, como gênero, raça, sexismo, racismo, que expõem as lutas antirracistas dos afrodescendentes na contemporaneidade.

\section{Referências}

BRASIL. Lei n ${ }^{\circ}$ 9.394, de 20 de dezembro de 1996. Estabelece as diretrizes e bases da educação nacional. Diário Oficial da União: República Federativa do Brasil: Poder Legislativo, Brasília, DF, 23 de dezembro de 1996. Disponível em: http://www.planalto.gov.br/ccivil_03/leis/L9394.htm. Acesso em: 23 jan. 2020.

Lei 10.639/2003, de 9 de janeiro de 2003. Altera a Lei $n^{\circ} 9.394$, de 20 de dezembro de 1996, afim de estabelecer o ensino de cultura e história africana e afrobrasileira. Diário Oficial da União: República Federativa do brasil: Poder Executivo, Brasília, DF, 9 de janeiro de 2003. Disponível em: http://www.planalto.gov.br/ccivil_03/leis/2003/L10.639.htm. Acesso em: 23 jan. 2020. 
DELEUZE, G. O que é um dispositivo? In: DELEUZE, G. O mistério de Ariana. Lisboa: Ed. Veja/Passagens, 1996.

DUARTE, E. de A. Literatura afro-brasileira: um conceito em construção. In: estudos de literatura brasileira contemporânea, Brasília, v. 1, p. 11-24, 2007. Disponível em: https: / /social.stoa.usp.br/articles/0037/3053/literatura_afrobrasileira_eduardo.pdf. Acesso em: 23 jan. 2020.

Entre Orfeu e Exu: a afrodescendência toma a palavra. In: DUARTE, E. de A.

(Org.). Literatura e afrodescendência no Brasil: antologia crítica. Belo Horizonte: Editora da UFMG, 2011, p. 13-48.

FOUCAULT, M. História da Sexualidade 1: a vontade de saber. Trad. Maria Thereza da Costa Albuquerque e J. A. Guilhon Albuquerque. 13. ed. Rio de Janeiro: Graal, 1999a. 155 p.

A arqueologia do saber. Trad. Luiz Felipe Baeta Neves. 7. ed. Rio de Janeiro: Forense Universitária, 2008a.

Genealogia e poder. In: FOUCAULT, M. Microfísica do poder. Trad. Roberto Machado. 26. ed. São Paulo: Graal, 2013a. p 262-277.

Sobre a história da sexualidade. In: FOUCAULT, M. Microfísica do Poder. Trad. Roberto Machado. 26. ed. São Paulo: Graal, 2013b. p. 363-406.

GELEDÉS - INSTITUTO DA MULHER NEGRA. Portal Geledés, 2020. Página inicial. Disponível em: https://www.geledes.org.br/. Acesso em 04 mai. 2020.

GONZALES, L. Racismo e sexismo na cultura brasileira. In: Revista Ciências Sociais Hoje. Fortaleza, p. 223-244, 1984.

GREGOLIN, M. do R. Discursos e imagens do corpo: heterotopias da (in)visibilidade na WEB. In: FLORES, G. G.; NECKEL, N. R. F.; GALLO, S. M. L. (Orgs.). Análise de discurso em rede: cultura e mídia. Campinas, SP: Pontes, 2015. p. 191-213.

FREYRE, G. Casa-grande \& senzala: formação da família brasileira sob o regime da economia patriarcal. 481. ed. São Paulo: Global, 2003.

IANNI, O. Literatura e consciência. In: Revista do Instituto de Estudos Brasileiros, São Paulo, v. 28, n. 1, p. 91-99, 1988.

NEVES, I. dos S. EtniCidades: os 400 anos de Belém e a presença indígena. Revista Moara, Belém, ed. 43, p. 26-44, 2015. Disponível em: https://periodicos.ufpa.br/index.php/moara/article/view/2634. Acesso em: 20 jan. 2020.

PROENÇA FILHO, Domício. A trajetória do negro na literatura brasileira. In: Estudos Avançados, São Paulo, v. 18, n. 50, p. 161-193, 2004.

SCHWARCZ, L. M. O espetáculo das raças: cientistas, instituições e questão racial no Brasil (1870-1930). São Paulo: companhia das Letras, 1993.

SILVIA NASCIMENTO. Mundo Negro, 2020. Quem somos. Disponível em: https://mundonegro.inf.br/quem-somos/. Acesso em: 04 mai. 2020. 